\title{
Exercise and Diet: The Unmentionable Truth
}

\section{Ilaria Peluso}

Centre of Nutrition, Council for Agricultural Research and Economics (CREA-NUT), Via Ardeatina 546, 00178 Rome, Italy.

\begin{abstract}
The viewpoint recently published on JAMA: "Exercise Is Medicine: At Any Dose?" should open a discussion similar to that summarized by "The big fat truth" published on Nature (2013). The tendency to give messages aimed to promote "healthy lifestyle behaviours", such as dietetic restrictions and exercise, could generate a population with commitment to general wellness, but at risk of eating disorders and over training syndrome.
\end{abstract}

The exciting title of the viewpoint "Exercise Is Medicine: At Any Dose?" [1] is unsatisfied by the conclusions of the work. Any medicine requires a therapeutic index. Eijsvogels and Thompson reviewed the works that evaluated the lowest effective dose of physical activity and the maximum tolerated dose of exercise [1]. Authors highlighted that "the current perception is that a curvilinear relationship exists between the amount of physical activity and the related health benefits". However, they concluded that the studies that suggested an attenuation of health benefits at higher physical activity doses had methodological flaws and that it is important for clinicians to keep emphasizing that exercise is a medicine. On the other hand, Toresdahl et al. [2] reported that the incidence of sudden cardiac arrest (SCA) in high school student athletes is higher (relative risk 3.65) than in student non-athletes and suggested that this finding may justify more advanced cardiac screening and improved emergency planning in schools. Furthermore, a condition known as the female athlete triad, characterized by low energy availability, functional hypothalamic amenorrhoea and osteoporosis, is commonly observed among athletes participating in leanness sports [3]. In fact, although the benefits of a regular and moderate physical activity are indisputable, it is well known that acute strenuous exercise may paradoxically induce oxidative stress and adverse effects on health, as it is documented that some immune system problems occur in athletes [4]. The book "Antioxidants in Sport Nutrition" [4] discusses the controversies surrounding the usefulness of antioxidant supplementation in the athlete's basic nutrition. Despite there is no a general agreement to the use of antioxidants for athletes, supplement use was reported by $64.7 \%$ of people who exercise at gyms [5]. Hildebrandt et al. [6] suggested that nutritional supplement use may be an important factor in the development of illicit illegal appearance and performance enhancing drugs (APED) use. In addition, eating disorders (ED), body image disturbance and specific aspects of perfectionism were also positively associated with the use of both supplements and illicit APED [6].

Although there is a lack of research on the prevalence of the overtraining syndrome (OTS) [3,7], the presence of ED among athletes has been relatively well studied [3]. The most common ED in athletes is anorexia nervosa (AN), which is a serious medical problem in young people in Western societies, and cardiovascular complications of AN can be present in up to $80 \%$ of cases [8]. Bar et al. [3] emphasized that it is important to realize that athletes show eating patterns or activity levels which may be reminiscent of "anorexic-like" behaviour, but do not technically fulfil the minimal diagnostic criteria. Moreover, it is likely that the reduction in exercise during the treatment of OTS will cause a person to increase anorexic behaviour in order to maintain low body weight levels [3]. Similarly it is very common to observe compensatory exercises during the treatment of ED [3]. A significant increase in the incidence of ED in the UK during the years 2000-2009 was found [9]. Besides, in Canada young children (aged 5 to 12 years) are seen with clinically significant restrictive eating disorders, with the incidence exceeding that of type 2 diabetes mellitus [10]. Although only $62.1 \%$ of children met the minimum criteria for the diagnosis of AN, some children who did not meet criteria for AN were medically compromised [10]. Furthermore, a dynamic prospective cohort study found that among men, both childhood underweight (odds ratio 5.20) and childhood obesity (odds ratio 4.66) increased the likelihood of adult metabolic syndrome [11].

However, the risk of the myth that "thinner is better" is often overlooked and the prevention of underweight and over-exercise is neglected, while the risk of physical inactivity is overestimated. In this context, Teleman et al. [12] were worried of the physical inactivity of the Italian university students because the results of the question "How often do you sport?" were: $25.8 \%$ never, $4.9 \%$ once per month, $19.3 \%$ once per week, $31.0 \%$ 2-3 days per week, $10.1 \%$ 4-6 days per week and $8.9 \%$ every day. However, considering the minimum levels of effectiveness for physical activity of vigorous ( 8 minutes per day) or moderate intensity ( 15 minutes a day), the latter also includes brisk walking and dancing [1], it is difficult to think that university students are completely physically inactive. On the other hand, despite data reported on body mass index (BMI), Teleman et al. [12] did not consider a major problem that $11.0 \%$ of the students were on a diet and another $28.0 \%$ expressed the fact that they were not currently on a diet but felt that they should have been. Considering that $13.7 \%$ of students were underweight, $75.1 \%$ were in the normal range, $9.8 \%$ were overweight, and $1.4 \%$ was obese, it would appear that the personal body perception is probably distorted in some cases (at least $27.8 \%)$.

In 2013 Hughes [13] summarized the discussion opened by the meta-analysis that found that relative to normal weight, grade 1 obesity was not associated with higher mortality, and overweight was associated with significantly lower all-cause mortality [14]. Although these results illustrate what is known as the obesity paradox, the scientific community discussed the risk of saying "what the real truth is", due to the fact that "preventing weight gain should be the primary public-health goal" [13]. The conclusion of Eijsvogels and Thompson: "No dose of vigorous physical activity is associated with higher mortality rates than physical inactivity" is in line with the message of public-health experts in the field of weight control. The discussion between Flegal and Willett reported by Hughes [13], relative to the study published in 2010 [15] which was not included in "Corresponding Author: Dr. Ilaria Peluso, Centre of Nutrition, Council for Agricultural Research and Economics (CREA-NUT), Via Ardeatina 546, 00178 Rome, Italy, Tel: +39-0651494560; E-mail: i.peluso@tiscali.it

Citation: Peluso I (2015) Exercise and Diet: The Unmentionable Truth. Int J Clin Nutr Diet 1: 104. doi: http://dx.doi.org/10.15344/ijcnd/2015/104

Copyright: () 2015 Peluso. This is an open-access article distributed under the terms of the Creative Commons Attribution License, which permits unrestricted use, distribution, and reproduction in any medium, provided the original author and source are credited. 
Flegal's analysis [14] because it did not use standard BMI categories, is of particular interest. Willett criticized the choice of the 'normal weight' (BMI 18.5-24.9) according to the criteria of the World Health Organization (WHO) as the reference category and the inclusion of smokers in the meta-analysis of Flegal. However, the study published on NEJM in 2010, involving healthy White participants who never smoked, reported that hazard ratios among women were similar for underweight (1.47 for a BMI of 15.0 to 18.4 ) and grade 1 obesity (1.44 for a BMI of 30.0 to 34.9), as well as for a BMI of 18.5 to 19.9 (1.14) and overweight (1.13 for a BMI of 25.0 to 29.9) [15], with a BMI of 22.5 to 24.9 as the reference category. Therefore an unexpressed message of this work could be: the "healthy BMI" should be between 22.5 and 24.9 , at least in women. However, this probably was not the message that the experts wanted to give because not in line with the idea 'It's very challenging to lose weight once you're obese. That's the most serious consequence of saying there's no problem with being overweight. We want to have people motivated not to get there in the first place" [13].

Similarly, the conclusion of Eijsvogels and Thompson [1] that physical activity is never harmful is consistent with the policy that promote the "healthy lifestyle behaviours".

It must be taken into account that a healthy lifestyle is the most frequent motivation to exercise (89.6\%) [5]. Consequently, the increasing media fixation and commercialization of "healthy lifestyle behaviours", such as dietary changes and exercise, could generate a population with commitment to general wellness, but at risk of ED and OTS.

\section{Competing Interests}

The author declare that she has no competing interests.

\section{References}

1. Eijsvogels TM, Thompson PD (2015) Exercise Is Medicine: At Any Dose? JAMA 314: 1915-1916.

2. Toresdahl BG, Rao AL, Harmon KG, Drezner JA (2014) Incidence of sudden cardiac arrest in high school student athletes on school campus. Heart Rhythm 11: 1190-1194.

3. Bär KJ, Markser VZ (2013) Sport specificity of mental disorders: the issue of sport psychiatry. Eur Arch Psychiatry Clin Neurosci 263 Suppl 2: S205210 .

4. Antioxidants in Sport Nutrition. Editor: Manfred Lamprecht. Boca Raton (FL): CRC Press; 2015

5. Lacerda FM, Carvalho WR, Hortegal EV, Cabral NA, Veloso HJ (2015) Factors associated with dietary supplement use by people who exercise at gyms. Rev Saude Publica 49: 63.

6. Hildebrandt T, Harty S, Langenbucher JW (2012) Fitness supplements as a gateway substance for anabolic-androgenic steroid use. Psychol Addict Behav 26: 955-962.

7. Meeusen R, Duclos M, Foster C, Fry A, Gleeson M, et al. (2013) Prevention, diagnosis, and treatment of the overtrainingsyndrome: joint consensus statement of the European College of Sport Science and the American College of Sports Medicine. Med Sci Sports Exerc 45: 186-205.

8. Di Cola G, Jacoangeli F, Jacoangeli F, Lombardo M, lellamo F (2014) Cardiovascular disorders in anorexia nervosa and potential therapeutic targets. Intern Emerg Med 9: 717-721.

9. Micali N, Hagberg KW, Petersen I, Treasure JL (2013) The incidence of eating disorders in the UK in 2000-2009: findings from the General Practice Research Database. BMJ Open 3

10. Pinhas L, Morris A, Crosby RD, Katzman DK (2011) Incidence and agespecific presentation of restrictive eating disorders in children: a Canadian Paediatric Surveillance Program study. Arch Pediatr Adolesc Med 165: 895-899.
11. Pimenta AM, Beunza JJ, Sanchez-Villegas A, Bes-Rastrollo M, MartinezGonzalez MA (2011) Childhood underweight, weight gain during childhood to adolescence/young adulthood and incidence of adult metabolic syndrome in the SUN (Seguimiento Universidad de Navarra) Project. Public Health Nutr 14: 1237-1244.

12. Teleman AA, de Waure C, Soffiani V, Poscia A, Di Pietro ML (2015) Physical activity and health promotion in Italian university students. Ann Ist Super Sanita 51: 106-110.

13. Hughes $\vee(2013)$ The big fat truth. Nature 497: 428-430.

14. Flegal KM, Kit BK, Orpana H, Graubard BI (2013) Association of all-cause mortality with overweight and obesity using standard body mass index categories: a systematic review and meta-analysis. JAMA 309: 71-82.

15. Berrington de Gonzalez A, Hartge P, Cerhan JR, Flint AJ, Hannan L, et al. (2010) Body-mass index and mortality among 1.46 million white adults. N Engl J Med 363: 2211-2219. 